\title{
Modeling and Simulation of Flexible Jet Transport Aircraft with High-Aspect-Ratio Wings
}

\author{
Ryan C. Kitson*, Christopher A. Lupp ${ }^{\dagger}$ and Carlos E. S. Cesnik ${ }^{\ddagger}$ \\ University of Michigan, Ann Arbor, MI, 48109
}

\begin{abstract}
Future transportation aircraft requirements focused on energy efficiency and environmental impact are leading to design concepts with very high-aspect-ratio wings. These slender wings aim to maximize efficiency by reducing drag and lowering structural weight, but can lead to larger structural deformations under aerodynamic loading and tighter coupling between the aeroelastic response and flight dynamics of the vehicle. Current engineering practice is to use wind tunnel testing to predict the stability and performance characteristics of the vehicle. However, the flutter boundary and mode maybe very different for a flexible vehicle in free flight compared to the cantilevered wing model alone. The coupled aeroelastic and flight dynamic response of an aircraft concept with a flexible high-aspect-ratio wing is investigated to better understand the nonlinear aeroelastic implications of these future design trends. This paper reports the impact of the aeroelastic and rigid body interaction on the free flight flutter boundary and vehicle response.
\end{abstract}

\section{Nomenclature}

A Autoregressive model matrix of linear coefficients

a Autoregressive model output coefficients

$H \quad$ Step response

$m \quad$ Point mass

$N \quad$ Total number of point masses

$r \quad$ Position vector of each point mass

$u \quad$ Model input

$Y \quad$ Column vector of autoregressive model output

y Model output

K Beam stiffness

M Beam moment

$\kappa \quad$ Beam curvature

$\sigma \quad$ Modal damping

$i \quad$ Autoregressive model time index

$i \quad$ Point mass index

$k \quad$ Step response time index, $1 \ldots n$

$x, y, z$ Body coordinate frame

$1,2,3$ Beam axis

\section{Introduction}

The FAA and NASA have developed technology programs to promote technology development focused on energy efficiency and environmental impacts, such as the Continuous Lower Energy, Emissions and Noise

*Ph.D. Candidate, Department of Aerospace Engineering, kitson@umich.edu; AIAA Student Member

$\dagger$ Ph.D. Pre-Candidate, Department of Aerospace Engineering, clupp@umich.edu; AIAA Student Member

¥Professor, Department of Aerospace Engineering, cesnik@umich.edu; AIAA Fellow 
(CLEEN) program and the Subsonic Fixed Wing project. The NASA Subsonic Fixed Wing project focuses on energy efficiency in terms of the vehicle aerodynamics, structures, and propulsion systems. Each discipline has specific technical challenges to reduce drag, structural weight, and fuel consumption. ${ }^{1}$ The energy efficiency of transport aircraft wing structures can be improved by using lightweight materials and highaspect-ratio wing designs to reduce structural weight and improve aerodynamic efficiency. However, these slender structures tend to be more flexible and have lower vibration frequencies. The structural modes with low natural frequencies can interact with the low frequency rigid body modes of the vehicle. Then the aeroelastic equations can no longer be seperated from the rigid body dynamics. Accurate modeling of the fluid, structure and flight dynamics interactions of these energy efficient high-aspect-ratio wing designs is critical to understanding the effects on vehicle stability and performance.

Transonic high-aspect-ratio wing aircraft will require accurate aerodynamic loads models to predict the flutter boundary and post-flutter response of the aircraft. Van Schoor and von Flotow emphasized the difference in predicted stability between a full unsteady aerodynamic analysis and a quasi-steady analysis for a subsonic high-aspect-ratio wing aircraft. ${ }^{2}$ The importance of using an unsteady aerodynamic model as well as modeling the turbulent viscous boundary layer was emphasized by Edwards for a cantilevered transport aircraft wing. ${ }^{3}$ Edwards used a computational method based on the transonic small disturbance equations with an analytical boundary layer model, but noted that the model had trouble converging for significant shock-boundary layer interactions. Therefore there is a need for a robust, unsteady, and viscous aerodynamic model will be required for design and analysis of future aircraft.

The importance of modeling the rigid-body dynamics for accurate stability calculations has been emphasized for multiple high aspect ratio configurations. ${ }^{2,4-6}$ In particular for flexible high-aspect-ratio wing aircraft it is important to solve the aeroelastic equations motion coupled with the rigid body dynamics. The interaction is associated with increased flexibility, lower structural frequencies, and applies to conventional and unconventional configurations. Examples of significant aeroelastic and rigid body interaction were presented by Livne and Weisshaar that include blended-wing-bodies, tube-and-wing, and joined-wing configurations. ${ }^{6}$ Britt, Jacobson and Arthurs discuss the development of the blended-wing-body B-2 bomber, which required a gust load alleviation control system for flight testing due to the significant interaction between the elastic and rigid-body degrees of freedom. ${ }^{4}$ For a flexible high-aspect-ratio wing aircraft, van Schoor and von Flotow showed that the predicted unstable mode is significantly altered by including elastic degrees of freedom by changing the flutter mode to a coupled bending/phugoid mode. ${ }^{2}$ These examples emphasize the need for aeroelastic analysis coupled with the rigid body dynamics for predicting vehicle stability.

Aeroelastic tailoring with lightweight composite materials can be used to change the structural properties of flight vehicles to achieve specific aeroelastic response characteristics. For high-aspect-ratio wings this aeroelastic tailoring is often focused on modifying the bend-twist coupling for a performance or stability benefit. A history of aeroelastic tailoring as well as some fundamental aeroelastic stability results was presented by Shirk, Hertz, and Weisshaar. ${ }^{7}$ Aeroelastic tailoring has a trade off between what is known as wash-in or wash-out bend-twist coupling. Wash-out is positive bending associated with negative twisting of the wing tip and can increase the divergence speed of the wing. Wash-in deformation has similar effects as sweeping the wing forward such as decreasing the divergence speed and increasing the flutter speed. Cesnik, Hodges, and Patil confirmed these trends by analyzing composite high-aspect-ratio wings with varying bendtwist coupling using a geometrically exact structural model and unsteady aerodynamic model. ${ }^{8}$ The nonlinear structural model showed a significant change in load distribution and deformation compared to a linearized structural model. Therefore, accurate stability analysis would need to be calculated about the nonlinear equilibrium state of the flexible high-aspect-ratio wing. In addition to divergence, flutter, and stress, the bend-twist coupling of a high-aspect-ratio wing can have a significant effect on the post-flutter response. A swept high-aspect-ratio wing in transonic flow was studied by Bendiksen and the results showed how the bend-twist coupling of the structure significantly changed the transfer of energy from the flow. ${ }^{9}$ This led to a stabilizing effect that changed the flutter and post-flutter response. Bendiksen's work used a nonlinear finite element model coupled with a finite element scheme for the Euler equations for a cantilevered wing. The previous studies regarding tailored structures show that results are dependent on accurately modeling the nonlinear aerodynamic loads and structural deformation. However, the aeroelastic tailoring effect on the aeroelastic and rigid body interactions have not been addressed.

This study investigates the aeroelastic stability of a high-aspect-ratio wing aircraft design concept in free flight and cantilever condition. The uCRM, a transonic transport aircraft, with an aspect-ratio of 13.5 is used 
in this study and is shown in Figure 1. The high-aspect-ratio wing is a departure from the aspect ratio 9 design that was originally presented by Vassberg et al. ${ }^{10}$ An aluminum and tow-steered composite wing structure were used to study the effect of aeroelastic tailoring on the high-aspect-ratio vehicle response and stability. The numerical modeling and simulation of UCRM is done within the University of Michigan Nonlinear Aeroelastic Simulation Toolbox (UM/NAST) that can simulate a fully flexible vehicle in free flight. The vehicle structure is modeled using geometrically exact beam finite elements and the unsteady aerodynamic loads are calculated using a reduced order model of the Navier-Stokes equations based on linear convolution of step responses. These reduced order models address the needs for geometrically exact structural modeling and unsteady viscous aerodynamic modeling discussed in the literature in a computationally efficient and robust way. UM/NAST solves the aeroelastic equations coupled with the six degree of freedom flight dynamics, which allows us to capture the interaction between the elastic and rigid body modes. The flutter boundary of the vehicle is calculated, which demonstrates the robustness of the reduced order model and the nonlinear behavior of aeroelastically tailored high-aspect-ratio wing transport aircraft.

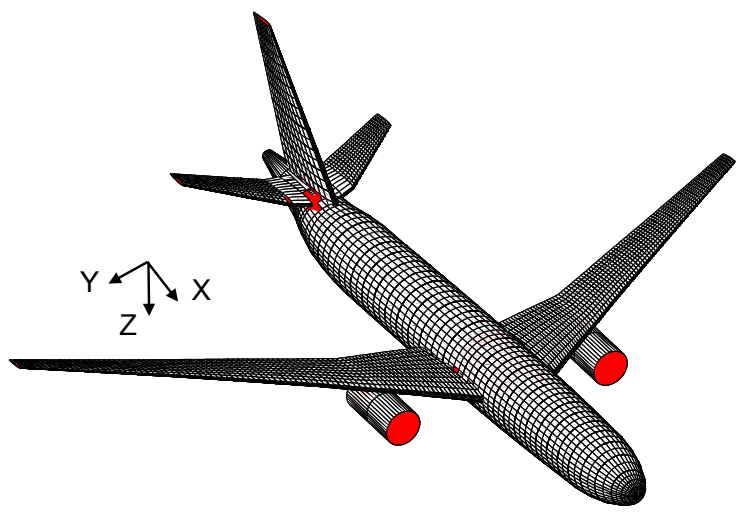

(a) Body frame coordinate system

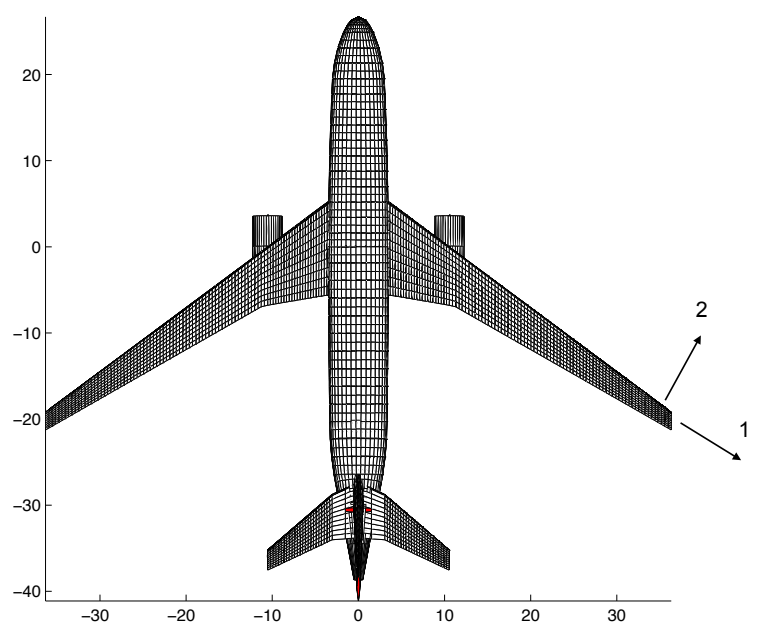

(b) Beam frame coordinate system

Figure 1. Isometric and top view of the UCRM model in UM/NAST (units: meters)

\section{Numerical Methods}

The tools and methods used to analyze the CRM nonlinear response to control inputs and stability are described next. The numerical framework UM/NAST is used to model and analyze the aircraft in free flight with the coupled nonlinear set of equations for its aeroelastic and flight dynamics. The structural model in UM/NAST uses a geometrically nonlinear beam finite element that can capture large deformations. The aerodynamic model in UM/NAST is based on the method of segments, ${ }^{11}$ which is a technique used to generate approximate aerodynamic models for flexible structures based on high-fidelity CFD data. This aerodynamic model discretizes the deformed wing into chordwise segments and uses the local properties to predict the aerodynamic loads. The unsteady aerodynamic loads are modeled using a linear convolution technique based on CFD step responses. The step response and the history of flow conditions are used with Duhamel's integral to calculate the loads at each time step. These structural and aerodynamic reduced order models were incorporated into the UM/NAST framework to calculate the time domain response of the vehicle.

The unsteady aerodynamic model is based on the time domain response therefore an autoregressive (AR) was used to calculate the vehicle stability based on the time history of the vehicle. This is in addition to a root locus method of calculating the stability that is limited to using a quasi-steady model in this framework. Together, these methods led to the stability analysis of the vehicle in free flight and compares the difference of including unsteady effects for this class of aircraft. 


\section{University of Michigan Nonlinear Aeroelastic Simulation Toolbox (UM/NAST)}

$\mathrm{UM} / \mathrm{NAST}$ is a computational framework that time marches the coupled aeroelastic system of equations for a vehicle in free flight using nonlinear beam finite elements to capture large deformations for very flexible structures. ${ }^{12}$ This is accomplished by using a nonlinear strain-displacement relation and has been verified for static and dynamic structural loading by using NASTRAN as the reference solution. ${ }^{13} \mathrm{~A}$ full aircraft is modeled in UM/NAST as a collection of the beam finite elements with structural and aerodynamic properties specified in the input file. Aerodynamic properties are defined by discretizing the lifting surfaces into spanwise sections and defining local aerodynamic properties for each section. This allows the user to define aerodynamic surrogates for each section. The structural equations of motion are coupled with the nonlinear six rigid-body equations of motion and the coupled system is marched forward in time. For the cases studied here, the trapezoidal integration scheme was used.

\section{Method of segments with linear convolution}

The method of segments creates a surrogate aerodynamic model for the lifting surfaces of an aircraft based on high-fidelity CFD results that will approximate the loading on the elastically deformed vehicle. The method was introduced by Skujins and Cesnik $^{11}$ and has been added to the UM/NAST framework for this study. This method begins by off-line running rigid CFD analyses on the aircraft at various flow conditions (Mach number and angle of attack). The wing is then divided into chord-wise segments and the pressure distribution for each segment is used to calculate the aerodynamic coefficients. Using this approach the deformed wing is viewed as a collection of independent segments with unique local flow properties. This method is similar to a strip-theory approximation except that it includes the effects of flow in the span-wise direction. Within UM/NAST the surrogate model generated by the method of segments is represented by a kriging surface for each wing segment. Kriging surfaces were chosen over other approximation techniques in anticipation of nonlinear aerodynamic phenomena due to high angles of attack and high Mach numbers. The inputs to the kriging surface include the local angle of attack, Mach number and control surface deflection. The kriging surface then outputs the approximate steady coefficients for lift, drag, and moment on the wing section.

The unsteady aerodynamics of the vehicle are approximated using a linear convolution technique with each chordwise segment along the wing. The unsteady model uses the convolution of the local angle of attack history with the segment's angle of attack step response to calculate the loads at a given time step. The step response is calculated offline with the full vehicle using a CFD solver and then the local responses are extracted from the full vehicle solution. This method is based on previous work by Raveh that showed how a step response as opposed to an impulse response could be used to calculate unsteady loads. ${ }^{14}$ During the vehicle simulation in UM/NAST the angle of attack history $u$ is used with the step response $H$ with the discrete version of Duhamel's integral to calculate the aerodynamic load at the current time step $y[n]$ as,

$$
y[n]=u[0] H[n]+\sum_{k=1}^{n}(u[k]-u[k-1]) H[n-k]
$$

The first term $u[0] H[n]$ represents the steady aerodynamic load at index 0 while the second term is the unsteady component due to an arbitrary input from index 1 to $n$. Therefore the steady term can come from a more accurate source such as the kriging surface and the unsteady contribution of the most recent time steps can be calculated using convolution. The result is a computationally efficient method of representing the CFD solution during the time marching analysis.

\section{Predicting flutter using an autoregressive model}

An autoregressive (AR) model is used to study the time domain response of the vehicle and determine the stability of the system. This approach was chosen because modeling the unsteady aerodynamics with the convolution technique as described above requires a time domain solution. McNamara and Friedmann have shown the AR model to be accurate and computationally effective compared to other time domain methods. ${ }^{15}$ The method of calculating flutter using an AR model was first presented by Pak and Friedmann. ${ }^{16}$ The method begins by taking the vehicle response in the time domain and fitting the $M$ autoregressive coefficients to the response data as, 


$$
y_{k}+\sum_{i=1}^{M} a_{i} y_{k-i}=0
$$

where $y_{k}$ is the output at index $k$ and $a_{i}$ is $i-t h$ autoregressive coefficient. Following Pak and Friedmann's work, the AR model can be re-written as a linear system:

$$
\{Y\}_{k+1}=[A]\{Y\}_{k}
$$

where

$$
[A]=\left[\begin{array}{ccccc}
-a_{1} & 1 & 0 & \ldots & 0 \\
-a_{2} & 0 & 1 & \ldots & 0 \\
\ldots & \ldots & \ldots & \ldots & \ldots \\
-a_{2 M-1} & 0 & 0 & \ldots & 1 \\
-a_{2 M} & 0 & 0 & \ldots & 0
\end{array}\right]
$$

and

$$
\{Y\}_{k}=\left\{\begin{array}{c}
y_{0} \\
y_{1} \\
\vdots \\
y_{k-1}
\end{array}\right\}
$$

The eigenvalues of this system are calculated for increasing values of dynamic pressure until the system becomes neutrally stable, which determines the flutter boundary. A MATLAB function for calculating the AR coefficients was used during this study for each vehicle response.

\section{Numerical Modeling}

A new vehicle was developed based on the NASA Common Research Model (CRM) ${ }^{10}$ with a higher aspect ratio (13.5) wing. The vehicle model is referred to as uCRM based on the undeformed reference configuration. The airfoil distribution and structural properties have been carefully modeled and serve as a baseline model for future high aspect ratio wing studies. The structural and aerodynamic reduced order models used for the vehicle are based on finite element and CFD models, which reduces the computational cost and improves robustness. The wing structure is the only component that is modeled with flexible elements while the fuselage, empennage, and engines are modeled with rigid elements. The aerodynamic properties are derived from the CFD model of the full vehicle with the body, wing, and horizontal tail. Then the method of segments and the linear convolution technique are used to create the aerodynamic reduced order model used for analysis. The mass and inertia of the full vehicle and engines were scaled to be similar to the Boeing 777-200ER aircraft as a representative transport vehicle. Cruise flight conditions of Mach 0.85 at $37,000 \mathrm{ft}$ were used to trim the aircraft and conduct the static and dynamic studies.

\section{A. Structural modeling}

The uCRM configuration is given as a three-dimensional finite element model. Therefore, to be able to conduct analyses in UM/NAST, the high fidelity model must be converted into an equivalent beam model. A top-view render of the UM/NAST model is shown in Figure 1 with the local beam axis label with axis 1 along the beam reference line, axis 2 towards the leading edge, and the 3 axis forming a right-handed coordinate system. Equivalent beam properties for the wing box are determined using FEM2STICK, a program developed by Aurora Flight Sciences and the University of Michigan for this effort. Stiffness properties are evaluated by applying tip moments to the structure in Nastran. The displacements of the reference beam are recovered using RBE3 interpolation elements and the stiffness matrix is determined according to Singh and Nichols. ${ }^{17}$

Consider $\kappa_{i}$ for $i=1,2,3$ being the curvature in the 1,2, and 3 directions respectively. For a known moment applied at the tip of the wing box, the curvatures may be retrieved from the displacements of the reference beam using finite differences and thus, the stiffness matrix is determined, that is: 


$$
\begin{gathered}
{[K]\{\kappa\}=\{M\}} \\
{\left[\begin{array}{lll}
K_{11} & K_{12} & K_{13} \\
K_{21} & K_{22} & K_{23} \\
K_{31} & K_{32} & K_{33}
\end{array}\right]\left\{\begin{array}{l}
\kappa_{1} \\
\kappa_{2} \\
\kappa_{3}
\end{array}\right\}=\left\{\begin{array}{l}
M_{1} \\
M_{2} \\
M_{3}
\end{array}\right\}}
\end{gathered}
$$

Mass properties are obtained by approximating the finite elements as point masses located at the center of the elements. A nearest neighbor approximation is used to obtain all point masses associated with a given beam section and the cross-sectional mass and inertia properties are calculated as

$$
\begin{aligned}
m & =\sum_{i=1}^{N} m_{i} \\
I_{11} & =\sum_{i=1}^{N} m_{i}\left(r_{2}^{2}+r_{3}^{2}\right) \\
I_{22} & =\sum_{i=1}^{N} m_{i}\left(r_{1}^{2}+r_{3}^{2}\right) \\
I_{33} & =\sum_{i=1}^{N} m_{i}\left(r_{1}^{2}+r_{2}^{2}\right) \\
I_{12} & =\sum_{i=1}^{N} m_{i} r_{1} r_{2} \\
I_{13} & =\sum_{i=1}^{N} m_{i} r_{1} r_{3} \\
I_{23} & =\sum_{i=1}^{N} m_{i} r_{2} r_{3}
\end{aligned}
$$

where $r_{i}$ represents the $i-t h$ component of the position vector of the point mass from the reference beam with respect to the beam frame $(1,2,3)$.

Two beam models have been created, one for the isotropic (aluminum), and the other for the orthotropic, tow-steered uCRM wing box. The tow-steered composite wing was aerostructurally optimized to minimize takeoff gross weight for the same vehicle (T. R. Brooks and J. R. R. A. Martins, personal communication, November 13, 2015). A comparison of the equivalent beam properties are presented in Figures 2 and 3.

To assess the dynamic behavior of the equivalent beam models, modal analyses were conducted for the equivalent beam and finite element models. Table 1 compares the resulting modal frequencies. Figure 4 compares the mode shape of the aluminum uCRM equivalent beam and Nastran models. Both the mode frequencies and mode shapes show good agreement, thus, affirming the use of the equivalent beam model.

Table 1. Comparison of mode frequencies between Nastran (full FEM model) and the NAST model with equivalent beam properties.

\begin{tabular}{lcc}
\hline Mode & Nastran & UM/NAST \\
\hline 1 & 0.80 & 0.83 \\
2 & 1.98 & 2.04 \\
3 & 2.95 & 2.98 \\
4 & 3.99 & 4.05 \\
\hline
\end{tabular}



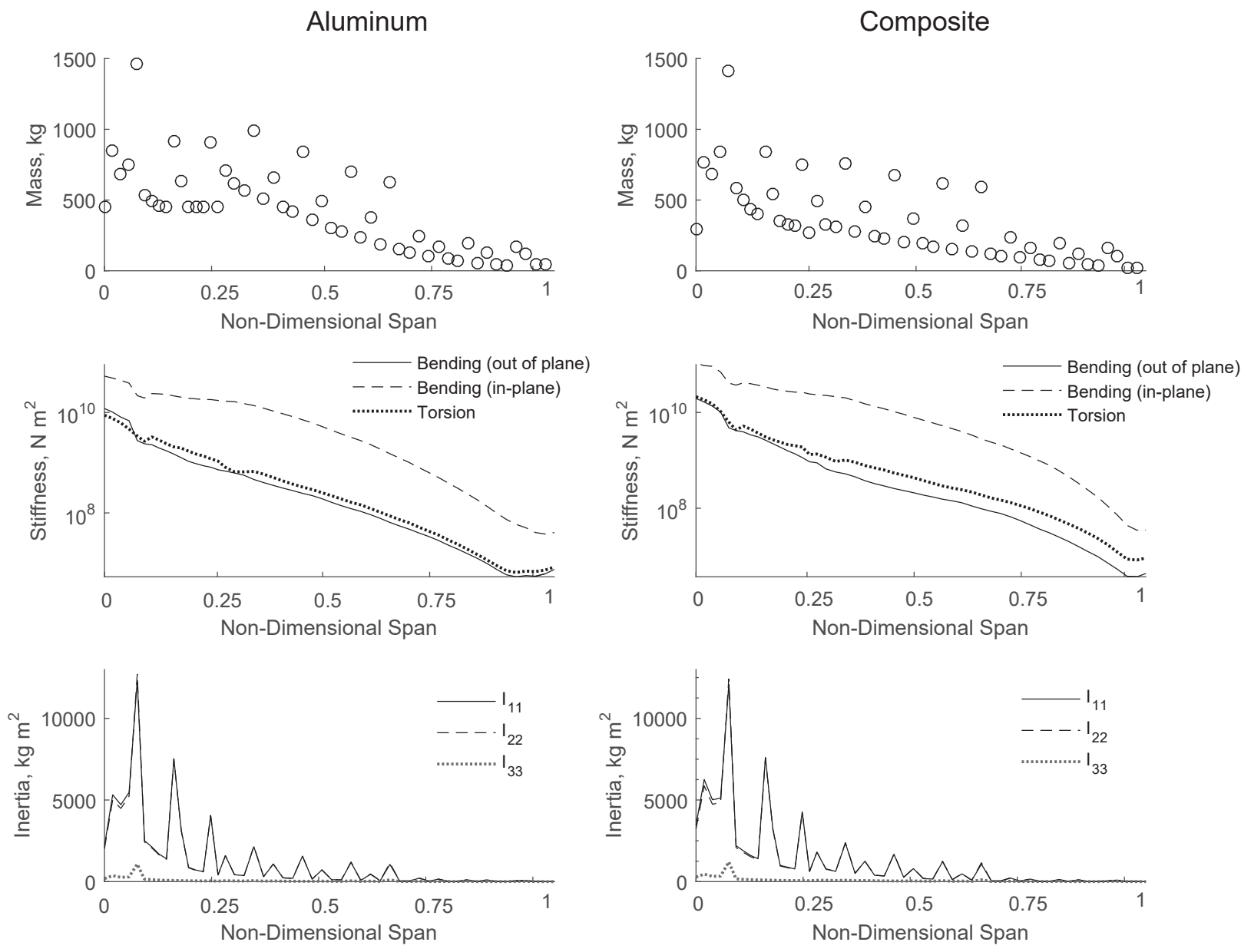

Figure 2. Comparison of the equivalent beam properties for the aluminum wing (left) and the tow-steered composite wing (right). 

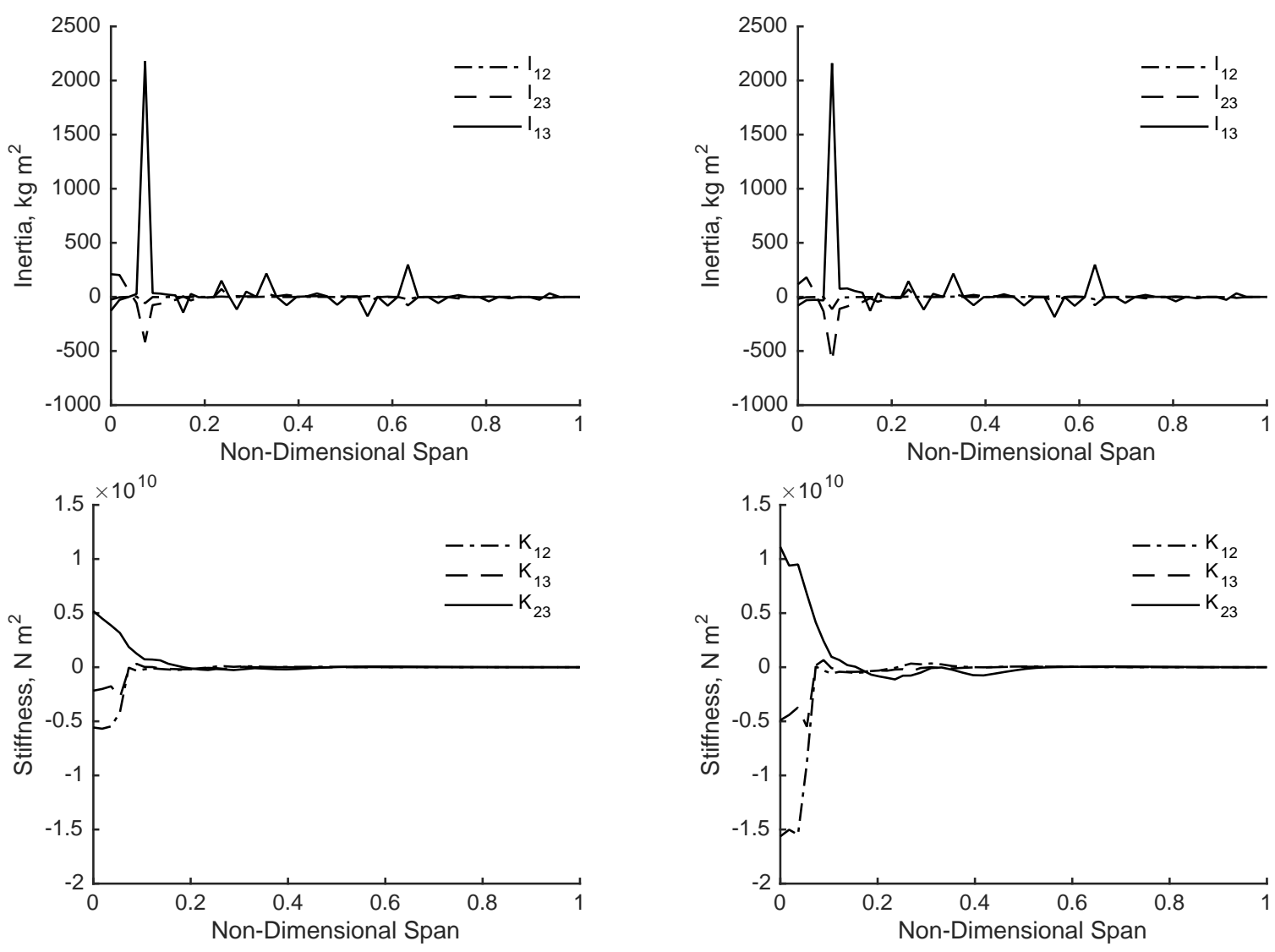

Figure 3. Comparison of the off-diagonal equivalent beam properties for the aluminum wing (left) and the tow-steered composite wing (right). 

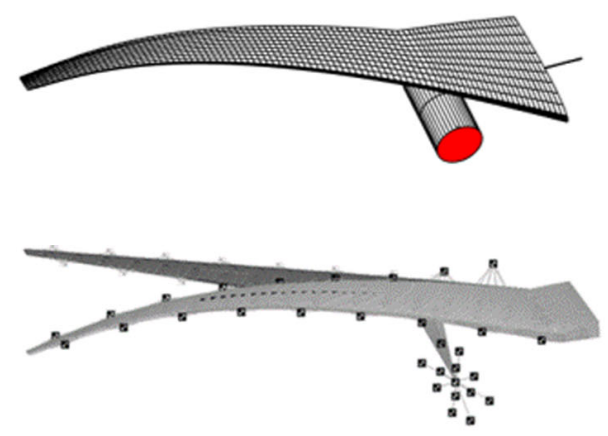

Mode 1

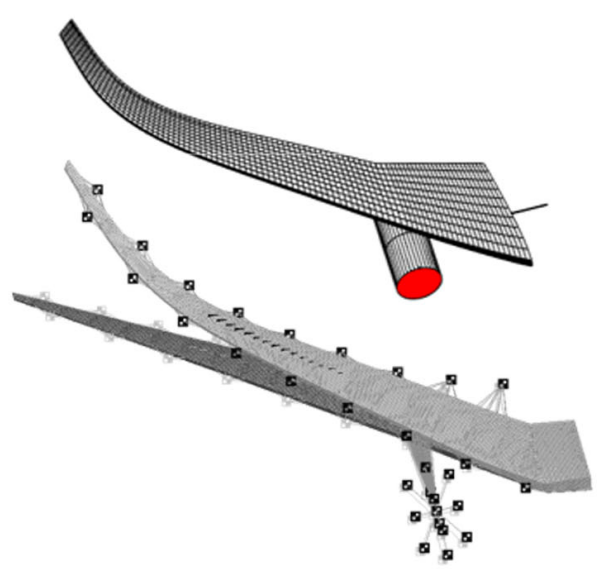

Mode 3
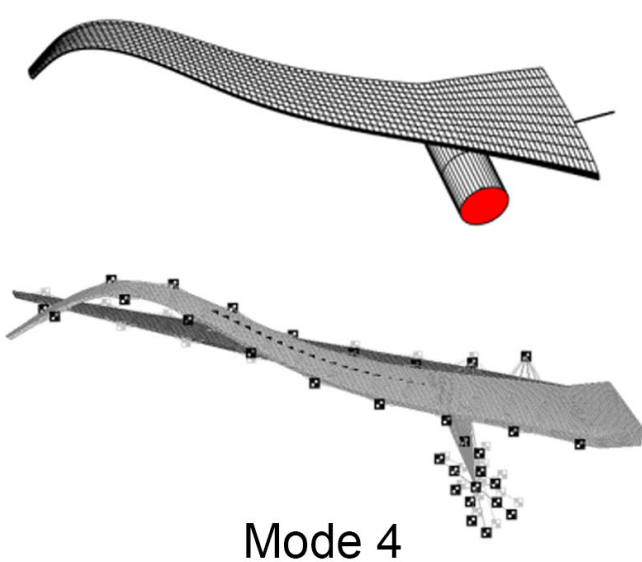

Figure 4. Comparison of the mode shapes determined using NAST with equivalent beam properties (above) and Nastran (below). 


\section{B. Aerodynamic modeling}

The aerodynamic model is based on the CFD solutions of the body-wing-tail configuration shown in Figure 5a. The CFD solutions were obtained using the Stanford University Unstructured ( $\left.\mathrm{SU}^{2}\right)$ CFD solver with the Reynolds averaged Navier-Stokes solver with the Spalart-Allmaras turbulence model. ${ }^{18}$ Steady-state and time-accurate CFD solutions were used to create the steady and unsteady aerodynamic models for static and dynamic analyses in UM/NAST.

During time-marching analysis the unsteady aerodynamic loads are modeled using a time-accurate CFD solution to a step input in angle of attack. The corresponding step response is included in the aerodynamic model and used during time-marching simulations with a convolution of the local angle of attack history to predict the aerodynamic loads.

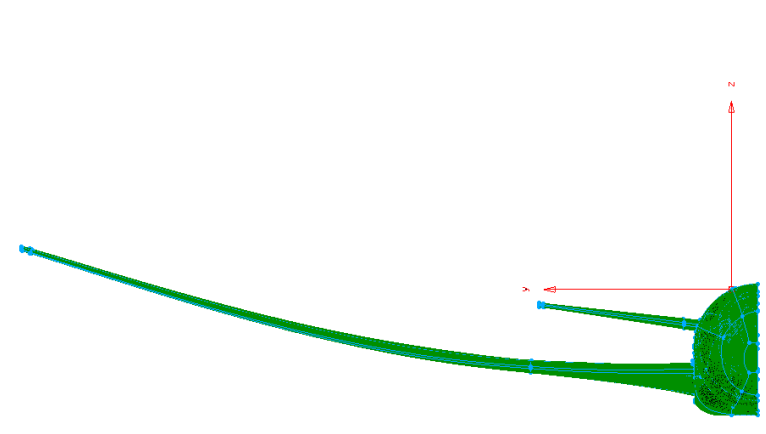

(a) CFD surface mesh of the 1-g shape

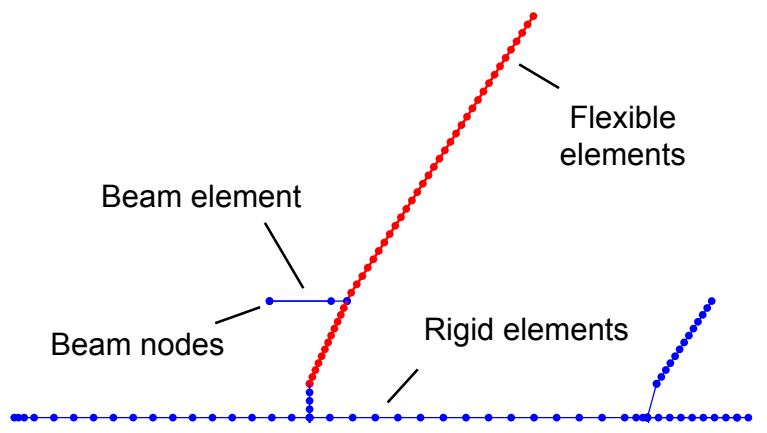

(b) UM/NAST beam finite element mesh (top view)

Figure 5. CFD and beam finite element mesh of the uCRM model

\section{Steady aerodynamic modeling}

Steady CFD solutions of the 1-g shape shown in Figure 5a from Mach 0.6 to cruise Mach 0.85 and angles of attack from -2.73 to 7.27 degrees are calculated to create the steady aerodynamic model of the wing. The steady-state surface flow solution of the wing is calculated using CFD for each combination of angle of attack and Mach number as in Figure 6a. Then the surface solution is sliced according to the beam finite element mesh in UM/NAST, shown in Figure 6b, and the aerodynamic coefficients (lift, moment, and drag) were calculated for each slice. A steady aerodynamic model is created for each beam finite element in the model, shown in Figure 5b, and uses a kriging surrogate to approximate the aerodynamic loads during static aeroelastic analysis. The DACE toolbox written for MATLAB was used to create the models with a first-order regression polynomial and a linear correlation function. ${ }^{19}$

The aerodynamic models are compared to the full CFD load distribution on the 1-g shape to verify the implementation. The load distribution for a flow condition that is used to create the model and an off-design condition to measure the accuracy of the approximation. The results in Figure 7 show that the surrogate reproduces the original training data and provides a close approximation to a sample off-design flow conditions.

\section{Unsteady aerodynamic modeling}

The vehicle step response is calculated for a 1 degree change in angle of attack from the cruise condition. The steady-state solution of the cruise flow conditions is used as the initial step with a grid that has been rotated by the angle of attack increment. The second order dual time-stepping method of $\mathrm{SU}^{2}$ is used to integrate the unsteady equations forward in time until the flow has reached a steady state. Then the surface flow solution for each time step is sliced according to the beam finite element mesh in UM/NAST, shown in Figure 6. The step response for each segment can be extracted by calculating the loads on each airfoil at each time step. During time-marching simulations in UM/NAST the convolution of the individual step response of each segment is convolved with the local angle of attack history to predict the aerodynamic loads.

The step responses of the full wing are shown in Figure 8 for the 1 degree change in angle of attack. 


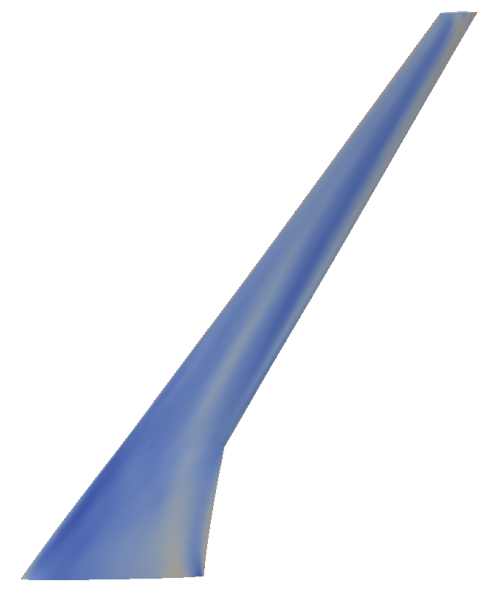

(a) CFD surface solution

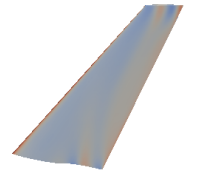

(b) CFD solution slices

Figure 6. CFD surface solution of the uCRM lifting surfaces and the slices used implement the method of segments
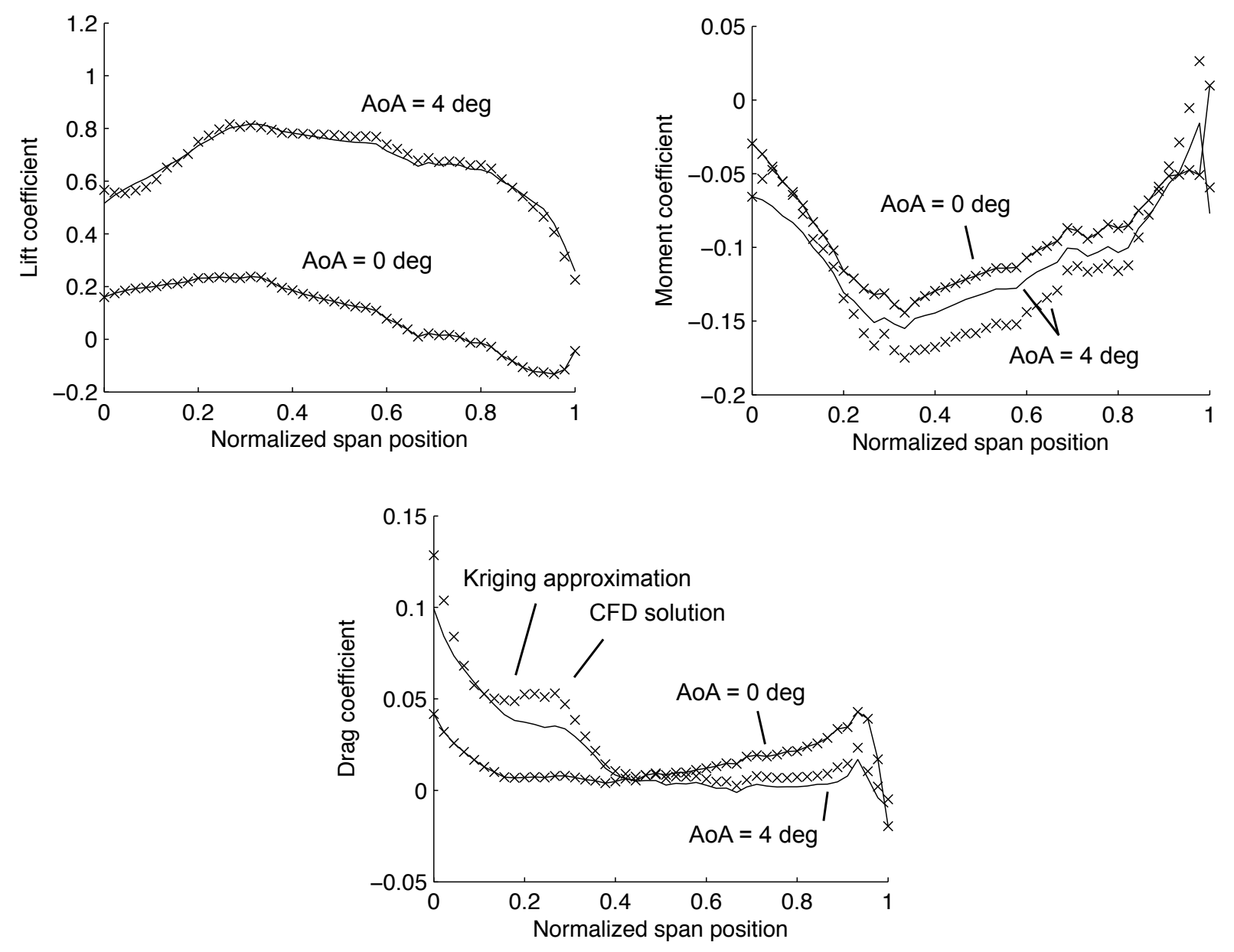

Figure 7. Comparing the kriging surface load distribution to a training point $(\mathrm{AoA}=0 \mathrm{deg})$ and a non-training point $(\mathrm{AoA}=4 \mathrm{deg})$ at Mach 0.85 

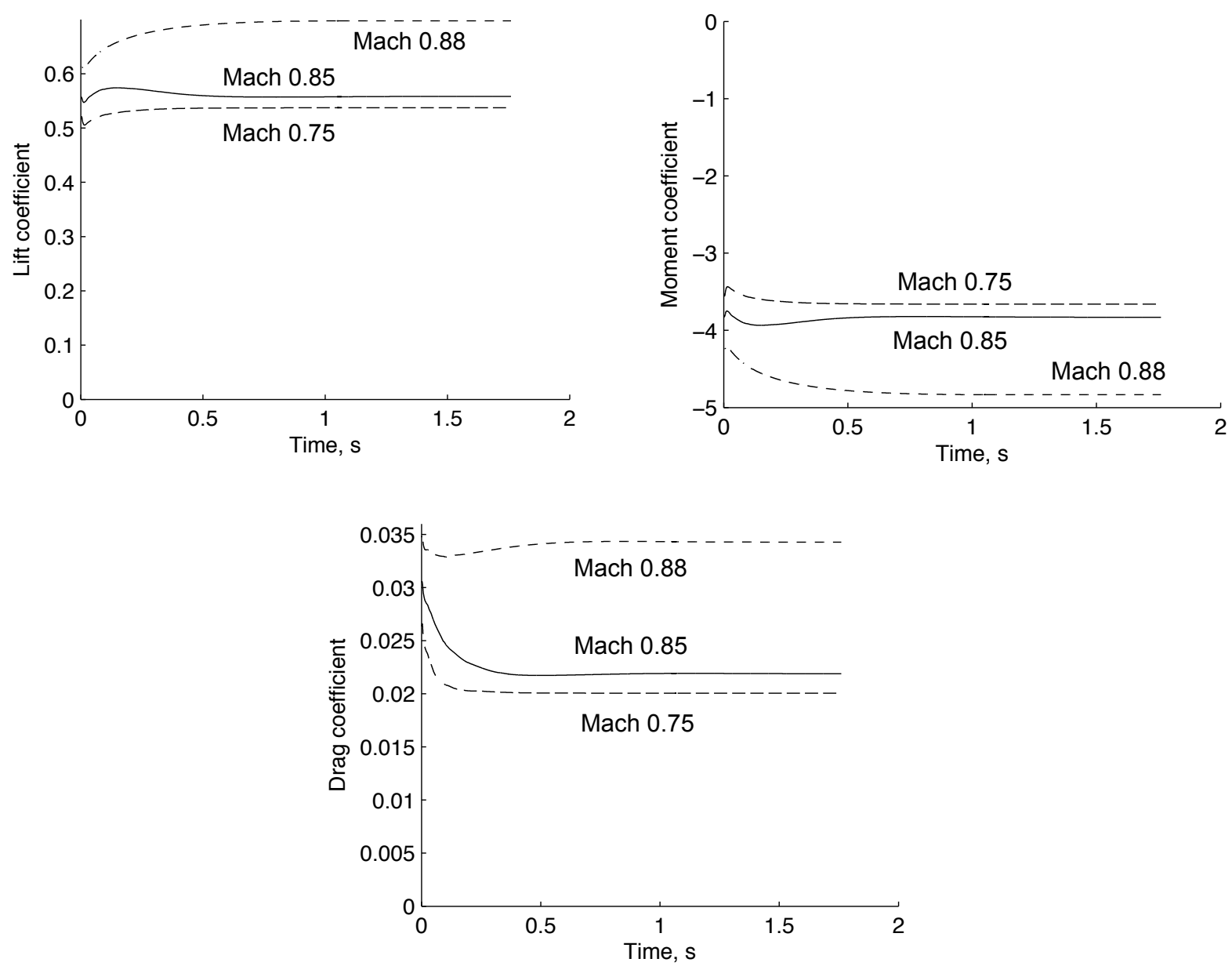

Figure 8. Step response of the wing to a 1 degree angle of attack increment 


\section{Vehicle modeling}

All other properties of the vehicle regarding the fuselage, engines, and empennage were based on a B777200ER aircraft, which is similar in size to the uCRM. The vehicle mass and inertia was based on aircraft design estimate methods for this class of aircraft ${ }^{20}$ and these properties of the full vehicle with aluminum and composite wings are listed in Tables 2 and 3, respectively.

Table 2. Mass and inertia properties of the UCRM vehicle with aluminum wings

\begin{tabular}{lcl}
\hline Parameter & Value & Units \\
\hline Total weight & $1.97 \times 10^{6}$ & $\mathrm{~N}$ \\
Engine weight & $7.41 \times 10^{4}$ & $\mathrm{~N}$ \\
Roll inertia & $9.40 \times 10^{6}$ & $\mathrm{~kg}-\mathrm{m}^{2}$ \\
Pitch inertia & $4.36 \times 10^{6}$ & $\mathrm{~kg}-\mathrm{m}^{2}$ \\
Yaw inertia & $1.34 \times 10^{7}$ & $\mathrm{~kg}-\mathrm{m}^{2}$ \\
\hline
\end{tabular}

Table 3. Mass and inertia properties of the uCRM vehicle with composite wings

\begin{tabular}{lcl}
\hline Parameter & Value & Units \\
\hline Total weight & $1.89 \times 10^{6}$ & $\mathrm{~N}$ \\
Engine weight & $7.41 \times 10^{4}$ & $\mathrm{~N}$ \\
Roll inertia & $7.45 \times 10^{6}$ & $\mathrm{~kg}-\mathrm{m}^{2}$ \\
Pitch inertia & $4.87 \times 10^{6}$ & $\mathrm{~kg}-\mathrm{m}^{2}$ \\
Yaw inertia & $1.20 \times 10^{7}$ & $\mathrm{~kg}-\mathrm{m}^{2}$ \\
\hline
\end{tabular}

\section{Numerical Results}

The response and stability of the aircraft are studied to understand the effect of flexibility due to high aspect ratio wings. First, a steady aeroelastic analysis of the aircraft response to an aileron input is presented to show the variation in aerodynamic loads due to the additional deformation without rigid body motion. Then a time simulation of the free vehicle with an aileron input is presented. The stability of the vehicle is then studied by calculating the eigenvalues of the aeroelastic system. This method is applied to the cantilever wing and to the free flight vehicle to study the impact of aeroelastic and rigid body coupling. However, the eigenvalue method does not include unsteady aerodynamics and a time domain method of calculating flutter is used instead to compare the stability calculations to the quasi-steady aerodynamic method.

\section{A. Aeroelastic response of the vehicle to aileron deflection}

The aeroelastic response to an aileron was measured to study the impact of flexibility on roll control authority of the vehicle. The aileron spans the last $25 \%$ of the wing and $25 \%$ of the chord from the trailing edge. Only the aerodynamic effects of the aileron deflection are modeled and no structural effects. The static aeroelastic response of the fixed vehicle shows how the load distribution on the wing is modified by deflecting the aileron. An asymmetric aileron deflection was used for the aluminum and composite wings to study the effect of non-isotropic in the material. The results in Figure 9 show that the deflection of the aluminum wing due to an aileron deflection causes a decreased change in the center of lift of the right and left wings. This is due to the increase torsional flexibility of the aluminum wing that leads to a loss in control effectiveness. Figure 11 shows the change in angle of attack for the left and right wings of the cantilevered aluminum and composite wings when the aileron is deflected 5 degrees. For the right wing, the higher flexibility of the aluminum causes a significant decrease in angle of attack reducing lift and the effect of aileron. The opposite effect is true for the left wing. This reduced control effectiveness leads to the reduced nonlinear roll moment response shown in Figure 10. The composite wing is stiffer than the aluminum which results in higher aileron effectiveness and a linear change in the vehicle roll moment. 

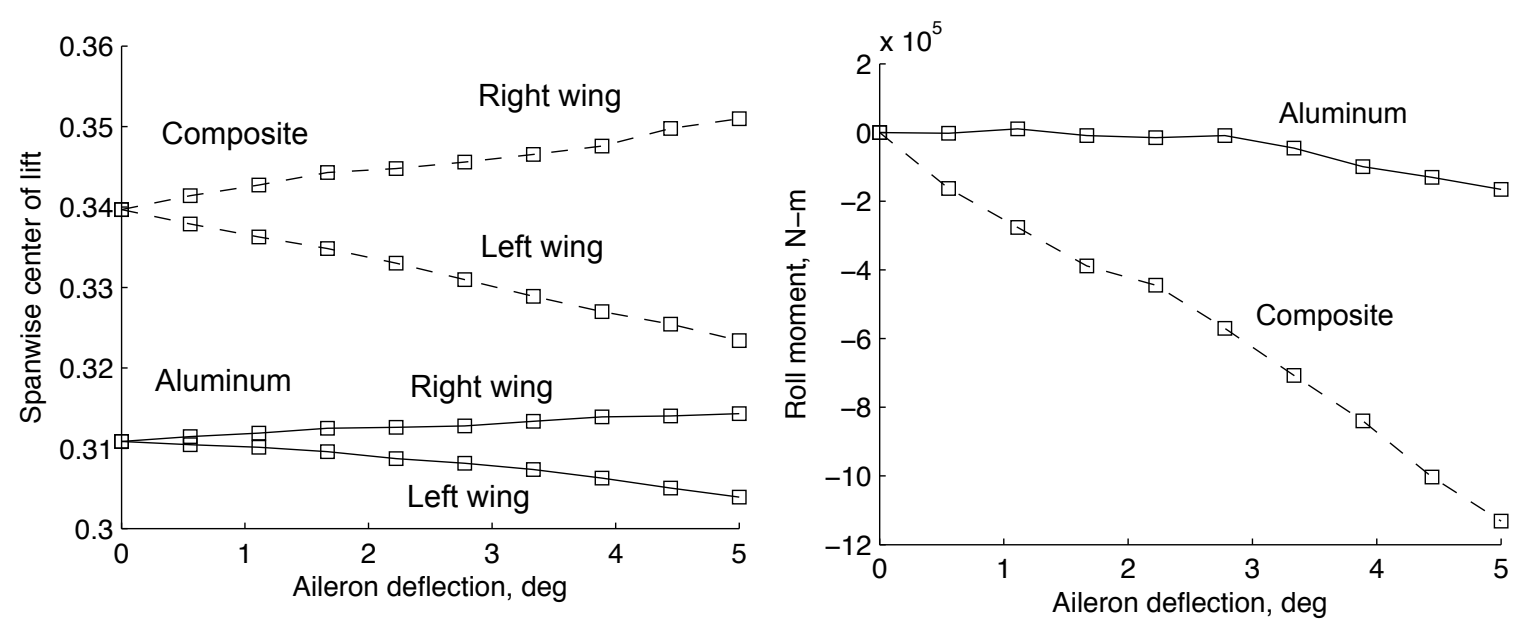

Figure 9. Center of lift (normalized by span) comparison between the aluminum and composite cantilever wings for various aileron deflections

Figure 10. Roll moment comparison between the aluminum and composite cantilever wings for various aileron deflections

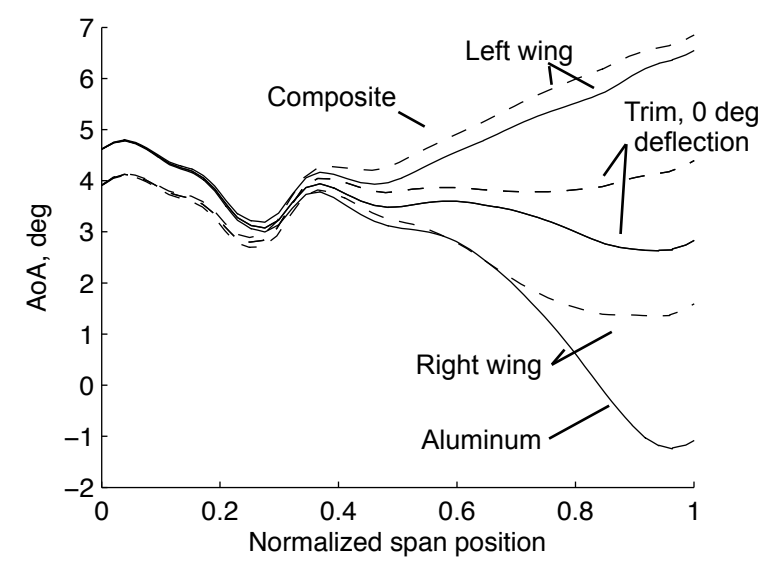

Figure 11. Angle of attack distribution at 0 and 5 degrees asymmetric aileron deflection for the aluminum and composite cantilever wings

An aileron input, shown in Figure 12, was applied to the aluminum and composite vehicle. The roll angle of both vehicles during the time simulation is shown in Figure 12. The aluminum vehicle has a lower roll rate and total roll angle compared to the composite wing for the same input.

\section{B. Stability of the high aspect ratio wing vehicle}

The flutter boundary of the aluminum-wing aircraft was calculated using two methods. The first method calculates a series of linearized systems at each dynamic pressure and the eigenvalues of the system determine the stability of the vehicle. The linearized method does not account for the unsteady aerodynamic effects and is based on a quasi-steady aerodynamic model although a correct deformation matching is achieved. Therefore, a time domain method based on the AR model is used to determine the vehicle stability including unsteady aerodynamics. In addition to comparing quasi-steady and unsteady aerodynamic models, the effect of rigid-body coupling is studied. The flutter boundaries of the cantilevered aluminum wing is compared to the free vehicle to study the impact of rigid-body degrees of freedom.

The first method of calculating the aeroelastic stability involves calculating the flutter dynamic pressure at various Mach numbers. For each Mach number the aerodynamic forces and structural displacements are used to calculate the linearized system of equations for the fixed or free-body system. The eigenvalues of this 
linearized system are used to determine the stability. When the real part of any eigenvalue is greater than zero the system is unstable and the dynamic pressure at which the real part is equal to zero corresponds to the flutter boundary. This method does not require any matching of the velocity with the Mach number and altitude. For each run the Mach number is set and the dynamic pressure is varied, which is effectively a change in density or altitude.

The second method of calculating the system stability uses the vehicle response in the time domain to include the unsteady aerodynamic effects. The flutter dynamic pressure is calculated for varying Mach numbers and normalized by the cruise dynamic pressure. For each tested Mach number the vehicle is trimmed and the initial static deformation is calculated to a specified tolerance. Then the equations of motion are marched forward in time for the free vehicle. The wing tip deflection is used as the output for the AR model and the eigenvalues of the AR linear system form determines the stability. The flutter boundary is the point when the real part of the eigenvalues move from negative to positive.

The flutter boundaries and frequencies of the cantilever wing and free vehicle using the quasi-steady and unsteady aerodynamic models are shown in Figure 13. The cantilever wing flutter boundary is higher than the free vehicle throughout the range of Mach numbers. In addition, the quasi-steady aerodynamic model predicts a higher flutter boundary than the unsteady aerodynamic model.

Figures 14 and 15 show the flutter modes of the cantilever wing and free vehicle, respectively, using the quasi-steady aerodynamic model. These modes are the eigenvectors of the linearized system at the flutter point for Mach 0.88 where the flutter points are slightly separated. The cantilevered wing mode is primarily an out-of-plane wing bending mode coupled with torsion while the free mode is an asymmetric bendingtorsion mode with a slight roll component. The free flutter mode at Mach 0.75, shown in Figure 17, is also an asymmetric bending-torsion mode with a smaller roll component.

The modal damping extracted from the AR model is used to either interpolate or extrapolate the flutter point at each Mach number as shown in Figure 18. These flutter points are less than the corresponding flutter points from the quasi-steady aerodynamics, but show the same general trend over the range of sampled Mach numbers.

\section{Concluding Remarks}

The impact of high-aspect-ratio wings on vehicle aeroelastic response and stability has been investigated for an isotropic aluminum and a tow-steered composite wing structure. A vehicle based on the Common Research Model (CRM) with aspect ratio 13.5 wing was used with both structures. Reduced order vehicle models of the CRM were created using nonlinear strain-based beam finite elements and a CFD-based aerodynamic surrogate model that includes unsteady aerodynamic effects. The vehicle models were used to study the aeroelastic response to an aileron deflection and the vehicle stability.

The static aeroelastic response of the aluminum and composite cantilevered wings show how the wing flexibility can lead to a nonlinear response and a loss in control authority. Beyond a certain aileron deflection the load distribution of the aluminum wing changes such that the moment about the center of gravity is less than expected based on a linear assumption. The composite wing did not show this nonlinear trend due to a higher stiffness and less wing deformation.

The aeroelastic stability of the vehicle was studied using two flutter calculation methods and two wing boundary conditions. The stability of the aluminum cantilevered wing was compared to the full vehicle stability with rigid-body coupling. A flutter prediction method based on the eigenvalues of the linearized aeroelastic system was used to calculate the flutter boundary and flutter modes of the fixed and free vehicle. In addition, a time-domain method using an autoregressive (AR) model was used so that unsteady aerodynamic effects could be included in the calculation. The unsteady aerodynamic model predicted lower flutter boundaries than the quasi-steady model in general. The results show some differences between analyzing the vehicle with and without rigid-body degrees of freedom for high-aspect-ratio wings. The rigid-body coupling appeared as a roll component with the asymmetric bend-twist mode of the wings. Further investigation is warranted between the cruise Mach number and the highest expected free stream Mach number to clearly define the boundary where rigid-body coupling begins.

The methods that have been developed here allow for robust and efficient analysis of flexible high-aspectratio wing vehicles through the use of reduced order models for unsteady aerodynamics and large structural deformations. As rigid-body coupling increases for these vehicles, the aerodynamics of the fuselage can be incorporated to more accurately capture the effects of rigid-body motion on the vehicle response and stability. 
One limitation to the framework is the magnitude of change in angle of attack along the lifting surfaces. As the change in angle of attack along the wing increases, the small perturbation assumption used for the linear convolution model becomes invalid. Working within the current framework, additional unsteady CFD step response solutions over the range of expected angles of attack would be required. Alternatively, the unsteady aerodynamic model could be extended from linear convolution to include a nonlinear correction factor that could be a function of the free stream and local flow conditions. ${ }^{11}$

\section{Acknowledgments}

The authors would like to thank Timothy Brooks and Gaetan Kenway from the University of Michigan's Multidisciplinary Design Optimization Laboratory for providing the original uCRM finite element model and outer mold line. This work was completed in part using the Air Force Research Laboratory and Army Research Laboratory Department of Defense Supercomputing Resource Centers as well as the Ohio Supercomputer Center. This work was supported in part by the NASA Advanced Air Transport Technology (AATT) High Aspect Ratio Wing (HARW) NRA Award (Karen Taminger and Carol Wieseman).

\section{References}

\footnotetext{
${ }^{1}$ Rosario, R. D., Follen, G., Wahls, R., and Madavan, N., "Subsonic Fixed Wing Project," 50th AIAA Aerospace Sciences Meeting, January 2012.

${ }^{2}$ van Schoor, M. C. and von Flotow, A. H., "Aeroelastic Characteristics of a Highly Flexible Aircraft," Journal of Aircraft, Vol. 27, No. 10, October 1990, pp. 901-908.

${ }^{3}$ Edwards, J. W., "Calculated Viscous and Scale Effects on Transonic Aeroelasticity," Journal of Aircraft, Vol. 45, No. 6, November-December 2008, pp. 1863-1871.

${ }^{4}$ Britt, R. T., Jacobson, S. B., and Arthurs, T. D., "Aeroservoelastic Analysis of the B-2 Bomber," Journal of Aircraft, Vol. 37, No. 5, September-October 2000, pp. 745-752.

${ }^{5} \mathrm{Su}, \mathrm{W}$. and Cesnik, C. E. S., "Nonlinear Aeroelasticity of a Very Flexible Blended-Wing-Body Aircraft," AIAA Journal, Vol. 47, No. 5, September-October 2010, pp. 1539-1553.

${ }^{6}$ Livne, E. and Weisshaar, T. A., "Aeroelasticity of Nonconventional Airplane Configurations - Past and Future," Journal of Aircraft, Vol. 40, No. 6, December 2003, pp. 1047-1065.

${ }^{7}$ Shirk, M. H. and Hertz, T. J., "Aeroelastic Tailoring - Theory, Practice and Promise," Journal of Aircraft, Vol. 23, No. 1, July 1984, pp. 6-18.

${ }^{8}$ Cesnik, C. E. S., Hodges, D. H., and Patil, M. J., "Aeroelastic analysis of composite wings," AIAA/ASME/ASCE/AHS/ASC Structures, Structural Dynamics and Materials Conference and Exhibit, AIAA 96-1444, April 1996.

${ }^{9}$ Bendiksen, O. O., "Transonic Limit Cycle Flutter of High-Aspect-Ratio Swept Wings," Journal of Aircraft, Vol. 45, No. 5, September-October 2008, pp. 1522-1533.

${ }^{10}$ Vassberg, J. C., DeHaan, M. A., Rivers, S. M., and Wahls, R. A., "Development of a Common Research Model for Applied CFD Validation Studies," 26th AIAA Applied Aerodynamics Conference, AIAA 2008-6919, 2008.

${ }^{11}$ Skujins, T. and Cesnik, C. E. S., "Reduced-Order Modeling of Unsteady Aerodynamics Acorss Multiple Mach Regimes," Journal of Aircraft, Vol. 51, No. 6, November-December 2014, pp. 1681-1704.

${ }^{12}$ Cesnik, C. E. S. and Su, W., "Nonlinear Aeroelastic Modeling and Analysis of Fully Flexible Aircraft," 46th AIAA/ASME/ASCE/AHS/ASC Structures, Structural Dynamics and Materials Conference, AIAA 2005-2169, 2005.

${ }^{13} \mathrm{Su}$, W. and Cesnik, C. E. S., "Strain-based Geometrically Nonlinear Beam Formulation for Modeling Very Flexible Aircraft," International Journal of Solids and Structures, Vol. 48, 2011, pp. 2349-2360.

${ }^{14}$ Raveh, D. E. and Mavris, D. N., "Reduced-Order Models Based on CFD Impulse and Step Responses," 42nd AIAA/ASME/ASCE/AHS/ASC Structures, Structural Dynamics, and Materials Conference, AIAA 01-1527, April 2001.

${ }^{15}$ McNamara, J. J. and Friedmann, P. P., "Flutter-Boundary Identification for Time-Domain Computational Aeroelasticity," AIAA Journal, Vol. 45, No. 7, July 2007, pp. 1546-1555.

${ }^{16}$ Pak, C. G. and Friedmann, P. P., "New Time-Domain Technique For Flutter Boundary Identification," AIAA Dynamics Specialists Conference, AIAA 92-2102, 1992.

${ }^{17}$ Singh, A. K. and Nichols, C. W., "Derivation of an Equivalent Beam Model from a Structural Finite Element Model," The MSC 1988 World Users Conference Proceedings, Vol. 1, No. 14, 1988.

${ }^{18}$ Palacios, F., Colonno, M. R., Aranake, A. C., Campos, A., Copeland, S. R., Economon, T. D., Lonkar, A. K., Lukaczyk, T. W., Taylor, T. W. R., and Alonso, J. J., "Stanford University Unstructured (SU2): An open-source integrated computational environment for multi-physics simulation and design," 51st AIAA Aerospace Sciences Meeting including the New Horizons Forum and Aerospace Exposition, AIAA 2013-0287, January 2013.

${ }^{19}$ Lophaven, S. N., Nielsen, H. B., and Sondergaard, J., "DACE Matlab Kriging Toolbox," Tech. Rep. IMM-TR-2002-12, Informatics and Mathematical Modelling Technical University of Denmark, August 2002.

${ }^{20}$ Roskam, J., Airplane Design Part V: Component Weight Estimation, Analysis and Research Corporation, 2003.
} 


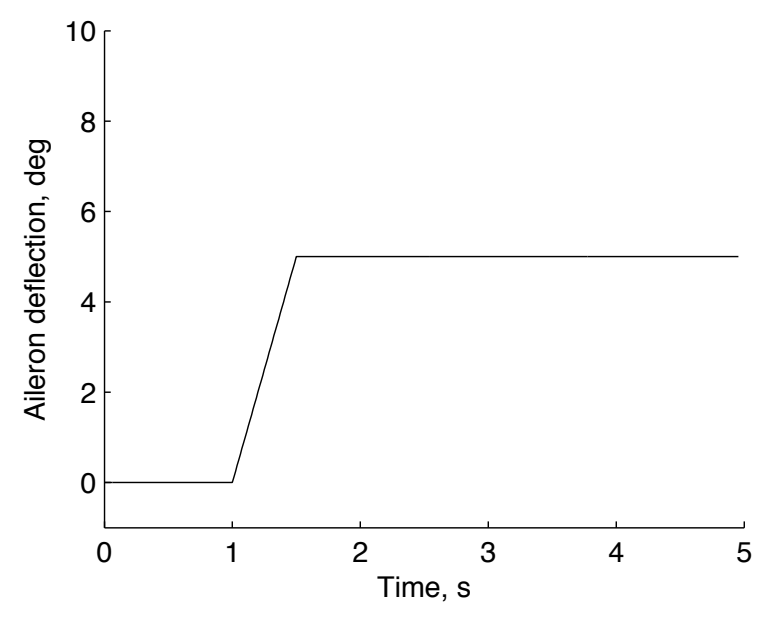

(a) Right Aileron Command

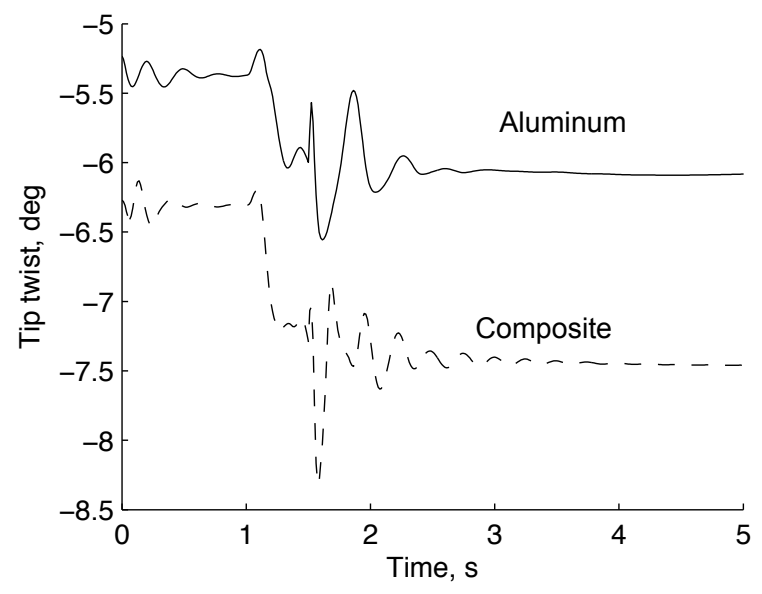

(c) Wing tip twist

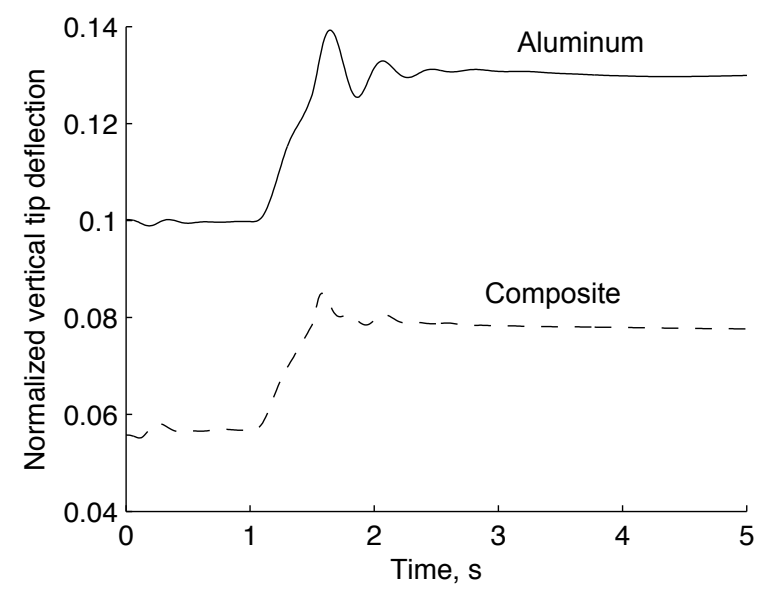

(b) Wing tip deflection

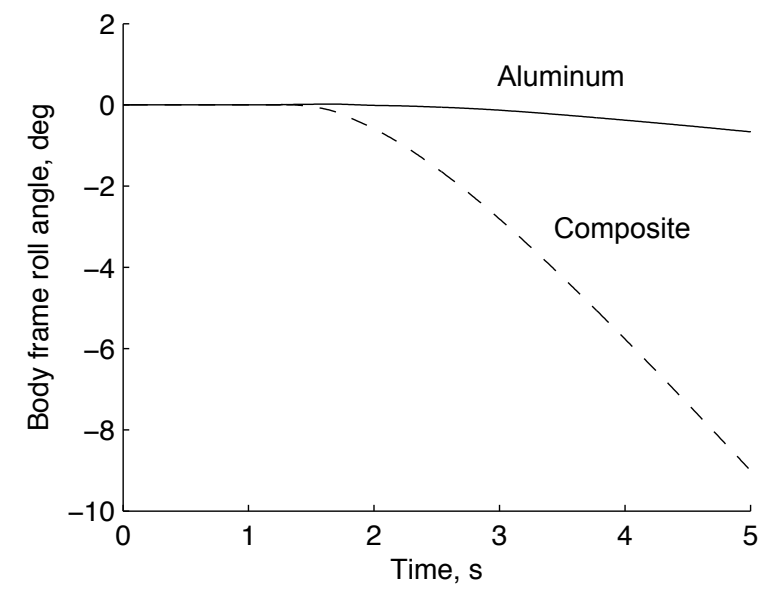

(d) Roll Angle

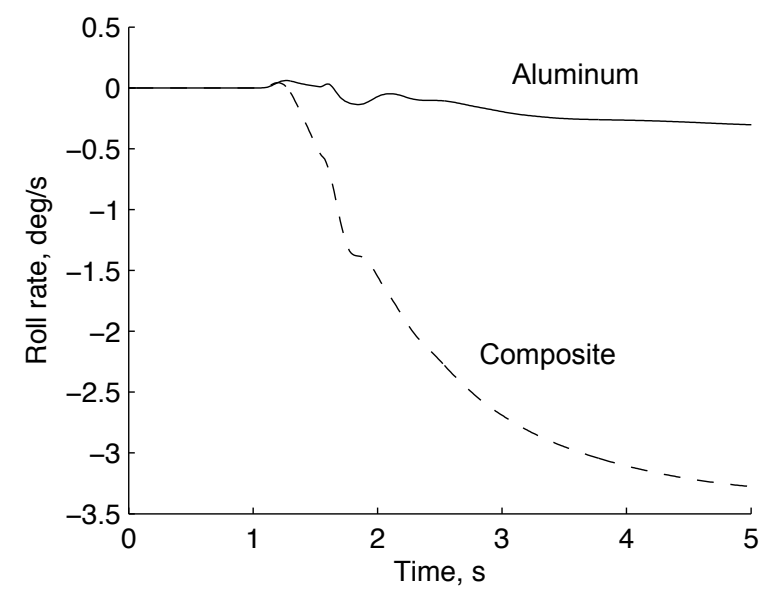

(e) Roll Rate

Figure 12. Vehicle response to an asymmetric aileron deflection 

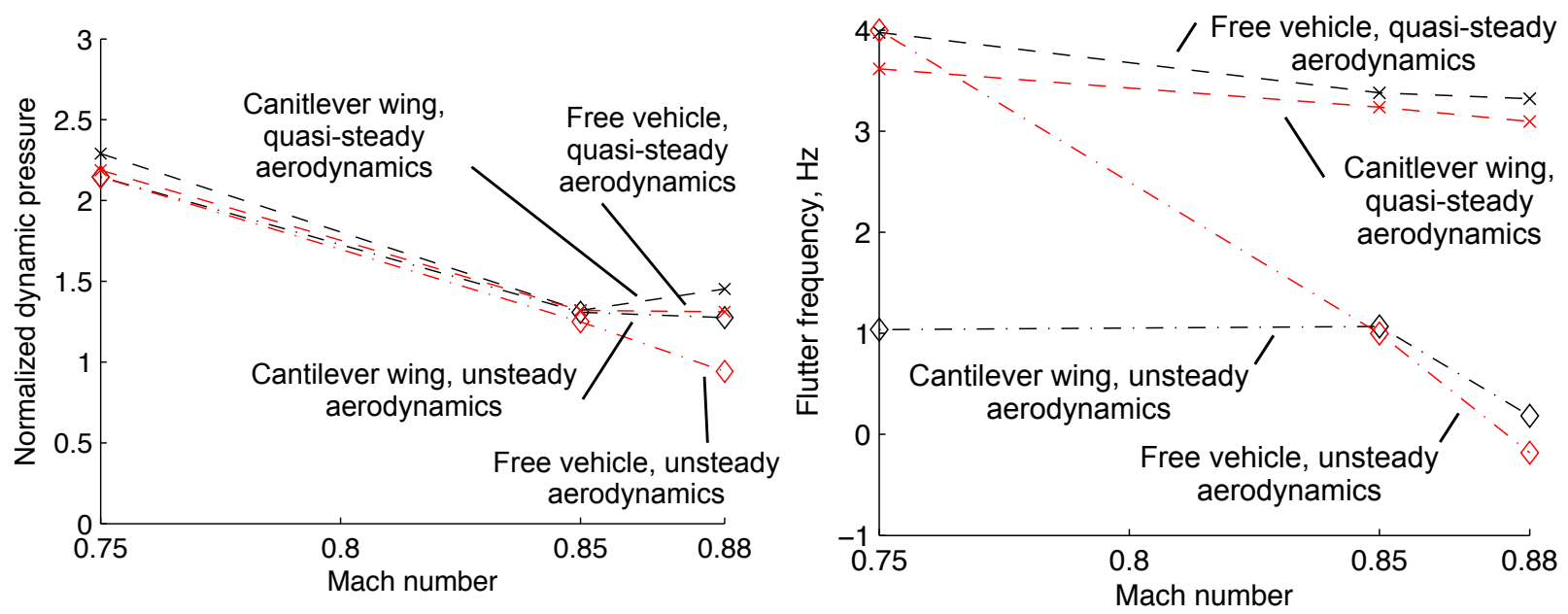

Figure 13. Flutter boundary and flutter frequencies of the cantilever wing and free vehicle using a quasi-steady and unsteady aerodynamic model (normalized by dynamic pressure at cruise condition: Mach 0.85 and 37,000 ft. altitude)
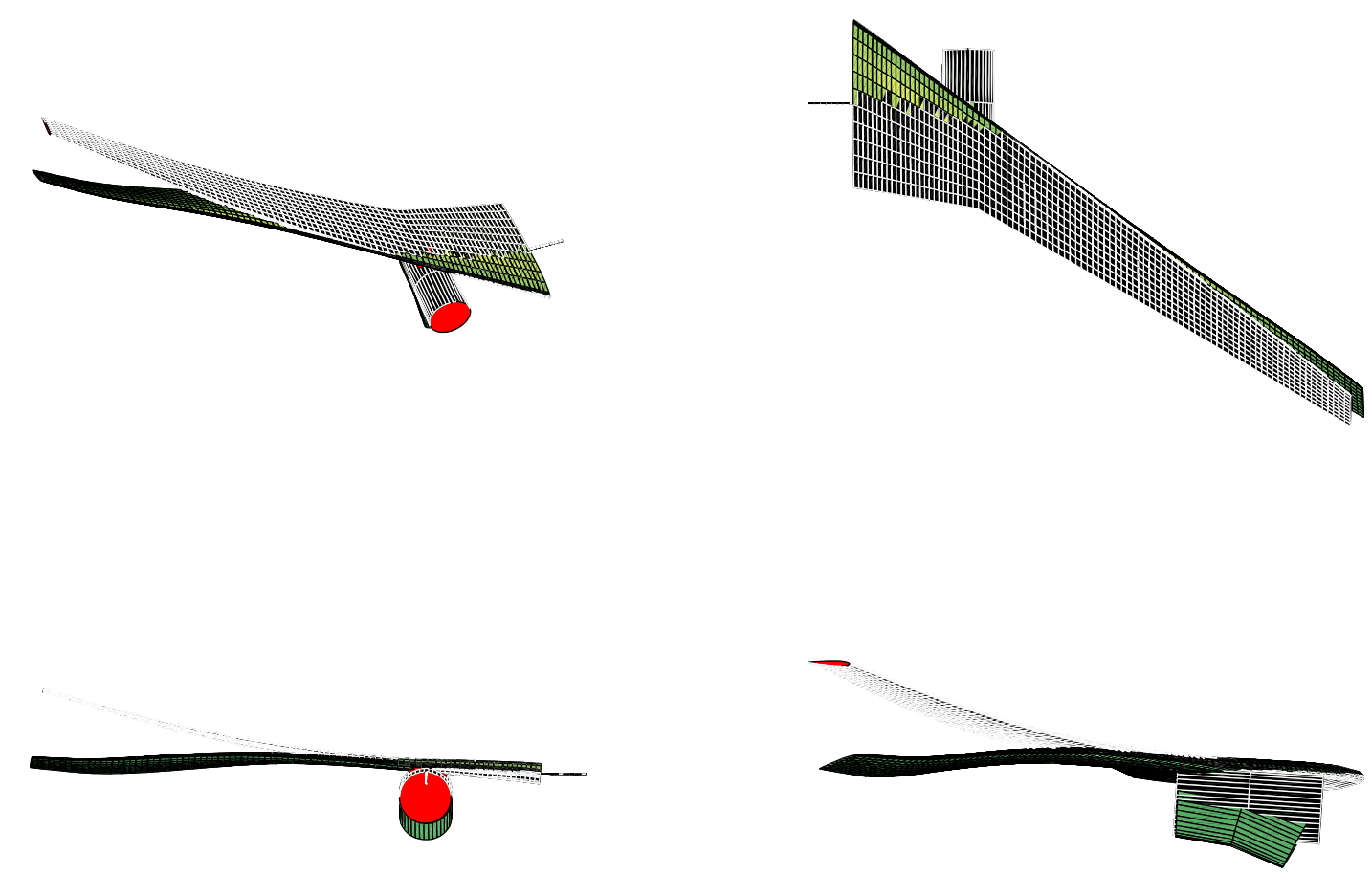

Figure 14. Flutter mode of the cantilever aluminum wing at Mach 0.88 

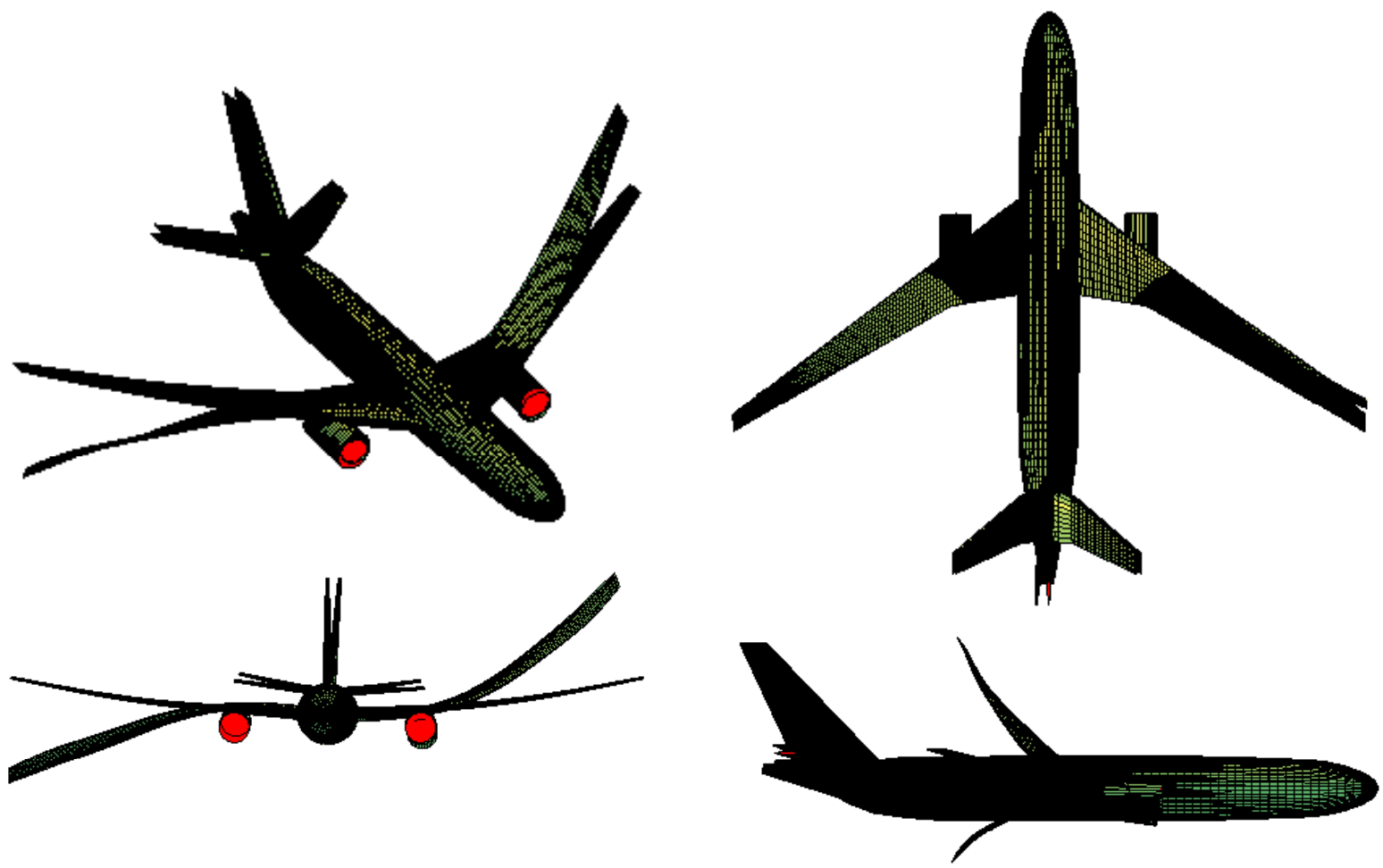

Figure 15. Flutter mode of the free-body aluminum vehicle at Mach 0.88 

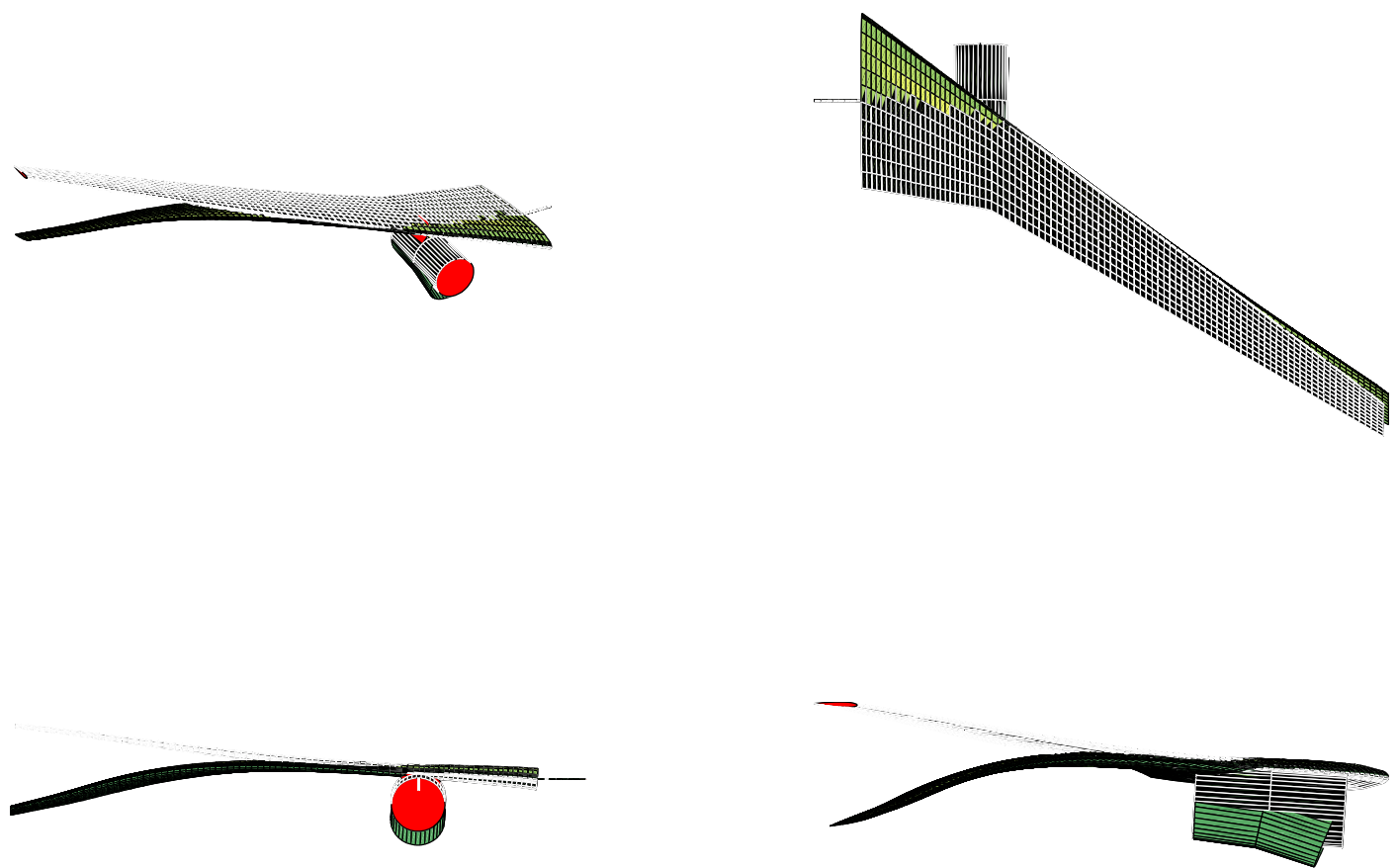

Figure 16. Flutter mode of the cantilever aluminum wing at Mach 0.75 

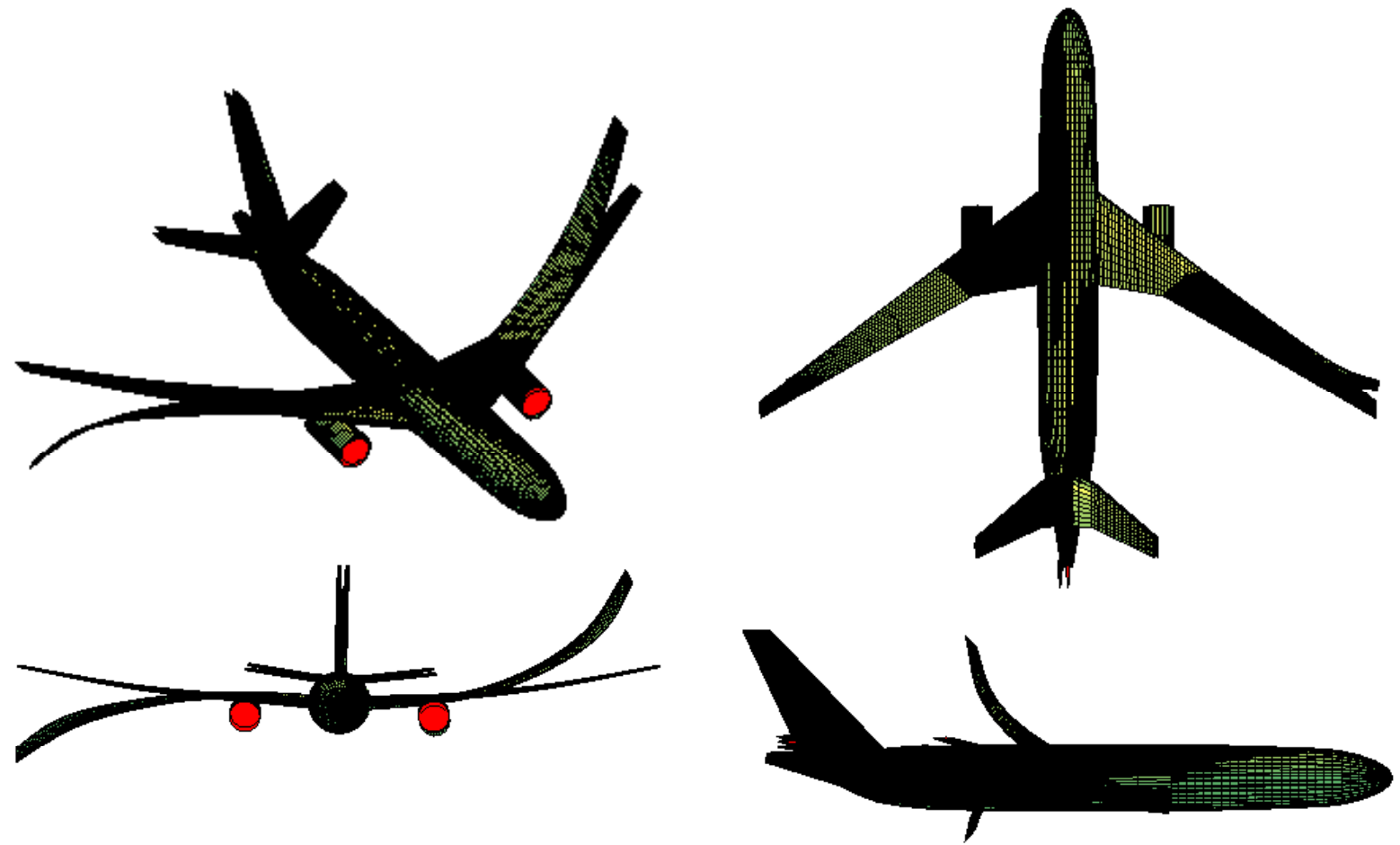

Figure 17. Flutter mode of the free-body aluminum vehicle at Mach 0.75

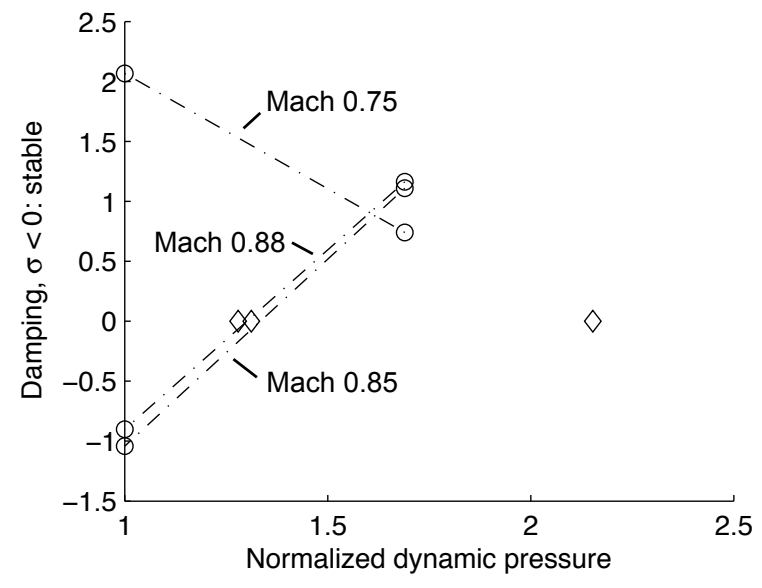

(a) Cantilever wing

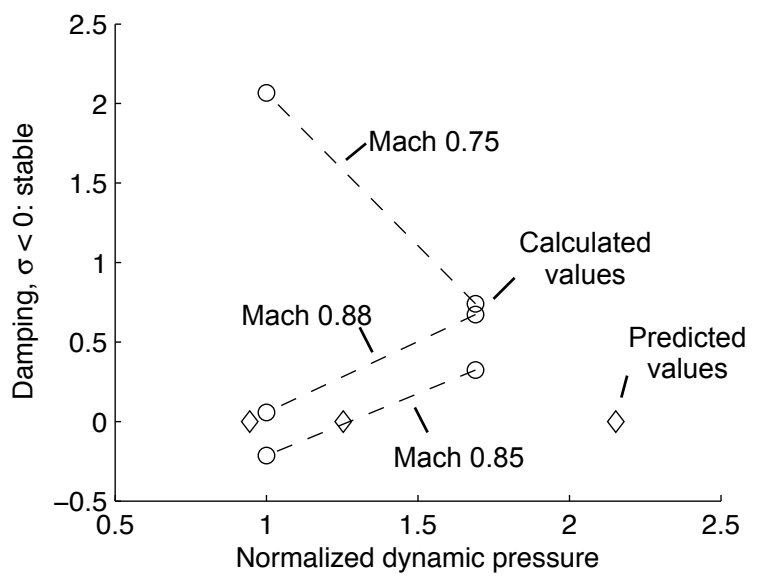

(b) Free vehicle

Figure 18. Damping values calculated using the AR model and the extrapolated flutter points for the aluminum cantilever wing and free vehicle cases 